\title{
Design of the "half-size" ITER Neutral Beam Source for the Test Facility ELISE
}

B. Heinemann ${ }^{1}$, H. Falter ${ }^{1}$, U. Fantz ${ }^{1}$, P. Franzen ${ }^{1}$, M. Fröschle ${ }^{1}$, R. Gutser ${ }^{1}$, W. Kraus ${ }^{1}$, R. Nocentini ${ }^{1}$, R. Riedl ${ }^{1}$, E. Speth ${ }^{1}$, A. Stäbler ${ }^{1}$, D. Wünderlich ${ }^{1}$, P. Agostinetti $^{2}, T$. Jiang ${ }^{3}$

${ }^{1}$ Max-Planck-Institut für Plasmaphysik, EURATOM Association, Postfach 1533, D-85740 Garching, Germany, ${ }^{2}$ Consorzio RFX, EURATOM Association, Corso Stati Uniti 4, I-35127 Padova, Italy,

${ }^{3}$ Southwestern Institute of Physics, ChengDu, China

* Correspond. author, Tel. +49 893299 2209, email: bernd.heinemann@ipp.mpg.de

\begin{abstract}
In 2007 the radio frequency driven negative hydrogen ion source developed at IPP in Garching was chosen by the ITER board as the new reference source for the ITER neutral beam system. In order to support the design and the commissioning and operating phases of the ITER test facilities ISTF and NBTF in Padua, IPP is presently constructing a new test facility ELISE (Extraction from a Large Ion Source Experiment).
\end{abstract}

ELISE will be operated with the so-called "half-size ITER source" which is an intermediate step between the present small IPP RF sources (1/8 ITER size) and the full size ITER source. The source will have approximately the width but only half the height of the ITER source. The modular concept with 4 drivers will allow an easy extrapolation to the full ITER size with 8 drivers. Pulsed beam extraction and acceleration up to $60 \mathrm{kV}$ (corresponding to pre-acceleration voltage of SINGAP) is foreseen.

The aim of the design of the ELISE source and extraction system was to be as close as possible to the ITER design; it has however some modifications allowing a better diagnostic access as well as more flexibility for exploring open questions. Therefore one major difference compared to the source of ITER, NBTF or ISTF is the possible operation in air. Specific requirements for RF sources as found on IPP test facilities BATMAN and MANITU are implemented [1]. 


\section{Key words}

neutral beam heating systems, negative ion source, radio frequency ion source, ITER

\section{Introduction}

The $\mathrm{rf}$ source development for negative hydrogen ions at IPP has achieved the ITER targets with respect to current density $\left(33 \mathrm{~mA} / \mathrm{cm}^{2} \mathrm{H}^{-}\right.$and $23 \mathrm{~mA} / \mathrm{cm}^{2} \mathrm{D}^{-}$at the calorimeter) and pulse length (1h) at the IPP testbeds BATMAN and MANITU, but still with small extraction areas of $70 \mathrm{~cm}^{2}$ and $200 \mathrm{~cm}^{2}$, respectively [1, 2, 3]. In addition a nearly half-size ITER plasma source has been constructed and operated since 2006 at the test facility RADI but only allowing plasma operation without extraction. It is devoted to define the rf-circuits and the geometry of the drivers. Furthermore it should demonstrate the homogeneity of large RF plasmas. However the extraction affects the plasma parameters in front of the plasma grid and influences not only the transport of negative ions and electrons, but also the Cs dynamics.

Therefore, IPP is planning to set up a new test facility ELISE for the extraction of a half-size RF-driven ion source ( parameters are shown in table 1). Stationary source operation is foreseen, while beam extraction can only be applied for 10 seconds every 3 minutes due to the limitations of the present IPP HV power supply. The current rating of the power supply is $50 \mathrm{~A}$ which will allow operation at the required ITER parameters (accelerated $30 \mathrm{~mA} / \mathrm{cm}^{2} \mathrm{H}^{-}$and $20 \mathrm{~mA} / \mathrm{cm}^{2} \mathrm{D}^{-}$) at low electron/ion ratios of $0.5(\mathrm{H})$ and $1.0(\mathrm{D})$, respectively [4].

ELISE is designed as a flexible and well diagnosed test facility. A large number of ports will allow spectroscopic and probe measurements at different positions of the source. Beam power and beam profile measurements will be done by a suitably instrumented target and doppler shift spectrometry. Further details are presented in [4].

ELISE is an important step between the existing small experiments at IPP and the full ITER NBI source; it supports the ITER design and helps to gain early experimental experience with beam extraction from a large rf source.

The test bed will use to a wide extent existing IPP infrastructure and hardware, e.g. the vacuum tank, cryo pump and cryo supply system, rf and HV power supply. The design has been made accordingly, an overview is shown in figure 1. For 
radiation protection ELISE will be placed inside a concrete housing of $9 \mathrm{~m} \times 6 \mathrm{~m}, 6 \mathrm{~m}$ high with a wall thickness of $0.7 \mathrm{~m}$ and therefore allowing a beam on time of approximately 2 hours/year (neutron dose $<1 \mathrm{mSv} / \mathrm{a}$ outside the protection building). The paper is concentrating on the design of the source, the extraction system and the high voltage insulator.

\section{Design overview}

The ion source of ELISE will be mounted onto the existing vacuum tank via an absolute gate valve (1250 mm inner diameter), which allows quicker source modifications without heating up and cooling down the cryo pumps. It also prevents the source from getting contaminated during the regeneration phase.

Figure 2 shows details of the ion source and the extraction system. The source at high potential $(-60 \mathrm{kV})$ is separated from the ground potential of the tank and the calorimeter by a main insulator. Unlike ITER the ELISE source will be operated mainly in air to facilitate diagnostic access in the region near the plasma grid and to ease external modification of confinement and filter field. Therefore the whole source and extraction system has to be a leak tight vacuum containment capable to take loads applied by the air pressure. The drivers can be operated in air for easier access again or be put under a vacuum dome to simulate the ITER condition, e.g. the insulation of the rf coils.

The extraction system of ELISE is a three grid system — plasma grid (PG), extraction grid (EG) and grounded grid (GG) - each consisting of two identical segments arranged in a flat plane. The size of one grid segments is about the same as one of the four grid segments for the full ITER size. Additionally a so-called bias plate is installed in front of the PG with "window frame" like openings around the beamlet groups $[4,5]$.

All grids are mounted on grid holder boxes which are nested inside each other and immersed into the source body similar to positive ion PINI design [6]. This design enables an absolutely flat surface of the plasma grid and allows good diagnostic access from all sides just above the grid surface. The grid holder boxes are supported against each other by ceramic post insulators and mounted as a unit to the 
high voltage ring. All water connections and cables are routed through insulated feedthroughs of the high voltage ring except the ground potential lines.

The grids and the bias plate are electrically insulated against each other as well as against the source body to allow biasing of the plasma grid against the source and to measure electrically all grid currents. In order to have some indication of the source homogeneity, the two segments of the extraction grid are also insulated against each other and against the grid holder box so that the (electron) current on these segments can be measured individually.

An electrostatic shield extends the ground potential into the HV ring in order to shield the beam from other potentials.

\section{Ion Source}

\subsection{Source Vessel}

The main design criteria for the source vessel was to build a thin walled vacuum containment with planar side walls and a minimum number of stiffening ribs, so that the source can be equipped with confinement and/or filter magnets in a flexible arrangement from outside. As a controlled wall temperature above $40^{\circ} \mathrm{C}$ was very beneficial for the Cs conditioning of the source on BATMAN and MANITU [2] all source components of ELISE will be kept at a temperature of $55^{\circ} \mathrm{C}$ (ITER design value).

Additionally a high number of diagnostic and supply ports are provided along all sides in two levels, so that the source depth can be increased by $54 \mathrm{~mm}$ by adding a spacer ring underneath the source base flange and using the second level of diagnostic ports at the position of the PG (figure 2).

The side wall is $15 \mathrm{~mm}$ thick in the region of the diagnostic ports, while the upper end is reduced to $6 \mathrm{~mm}$ thickness. Deep drilled cooling channels of $\varnothing 3 \mathrm{~mm}$ inside all walls will be machined in the direction of the source axis. The machining and welding of the upper and lower ends of the walls to the flanges form manifolds along the circumference of the source at both ends and also at the connection between the thin and the thick wall area (figure 3). Two water inlets are machined radially in the corners of the drivers plate flange and two water outlets are machined in the source base flange in the opposite corners. 
The inner surface of the vessel is completely coated with copper of $1 \mathrm{~mm}$ thickness, which is electro deposited onto the wall. The purpose of this layer is to distribute and conduct local heat loads towards the cooling channels. Such "hot spots" might be caused by plasma particles following the field lines of the magnets.

Hydraulic calculations of the water circuit as well as thermal calculations of a local model have been performed by ANSYS. With a given water flow of 11 1/s the pressure drop has been calculated to be 4.7 bar and the velocity in the cooling channels between $9 \mathrm{~m} / \mathrm{s}$ and $17 \mathrm{~m} / \mathrm{s}$. The non-uniformity is caused by the limited space available for the manifolds but is not considered to be critical as the power load on the inner wall is relatively low $\left(70 \mathrm{~kW} / \mathrm{m}^{2}\right)$.

The concept of design and manufacturing has been tested successfully for the sources of BATMAN, MANITU and RADI.

The source vessel is closed at its rear end by the so-called driver plate which supports the four drivers (figure 4). The driver openings have a large chamfer to ease the flow and the distribution of the plasma into the source vessel. An intensive cooling is foreseen to remove the heat load from the plasma and back streaming positive ions. This heat load has been downscaled from the ITER value of $880 \mathrm{~kW} \mathrm{[7]}$ to $26.4 \mathrm{~kW}$ for the ELISE size and acceleration voltage $(60 \mathrm{kV})$. The cooling channels are milled into the stainless steel back plate and closed by a $1 \mathrm{~mm}$ thick electro deposited copper layer, also along the cone. The cooling circuits are divided into 4 cycles with two inlets and 4 outlets and thus allow independent calorimetric measurements for each driver region.

The $\mathrm{Cu}$ layer will be PVD coated with $3 \mu \mathrm{m}$ thick molybdenum to avoid sputtering of copper by the plasma and back streaming ions. The sputtering may lead to an increase of impurities inside the source and therefore affect the work function of the Cs coated surfaces. Mo coating of the inner surfaces of MANITU has improved the source performance considerably [8].

\subsection{Driver}

The driver itself consists of a cylinder made of $\mathrm{Al}_{2} \mathrm{O}_{3}$ or quartz with an outer diameter of $300 \mathrm{~mm}$, a wall thickness of $8 \mathrm{~mm}$ and a length of $140 \mathrm{~mm}$. This cylinder is in no direct contact with the metal flanges, but floating between two O-rings which 
protect the driver from mechanical damage. An overview of the driver is presented in figure 5 .

The back side of the cylinder is closed with the driver back plate which is supported by four rods from the driver plate. It is made from aluminium and equipped outside with a cooling loop and inside with a pattern of permanent magnets $(9 \mathrm{~mm} \mathrm{x}$ $13 \mathrm{~mm}$ ) in a chequer board configuration. The feedthroughs for starter filament, gas supply and diagnostics are positioned off center to protect them between the beamlet groups against back streaming ions.

The RF coil is wound around the driver cylinder. The number of windings and the insulation material are still subject to tests at MANITU and RADI. The initial configuration at ELISE will probably be the standard coil made out of a copper tube $\varnothing$ $6 \times 1 \mathrm{~mm}$ insulated by a PTFE tube and having 4.5 to 6.5 windings.

The inner part of the driver is protected against erosion by an actively cooled faraday shield [9] which is a thin walled structure manufactured completely by electro deposition of copper. The design has been performed and tested at IPP Garching. It consists of a back plate with two layers of spider like manifolds on top of each other, one acting as the water inlet and one as outlet manifold. They are connected to the cylindrical side wall where they feed always four stripes in series with cooling water. The side wall is only $3 \mathrm{~mm}$ thick and incorporates the cooling channels and "step formed" slits between the 80 stripes ( $\sim 10 \mathrm{~mm}$ wide) to protect the outer quartz or $\mathrm{Al}_{2} \mathrm{O}_{3}$ cylinder from a direct line of sight to the plasma. All inner surfaces of the faraday shield will be coated again with $3 \mu \mathrm{m}$ of Mo to prevent $\mathrm{Cu}$ sputtering [8]. The water feedthroughs to the outside of the driver are stainless steel stubs which are also embedded inside the copper during the manufacturing process.

\section{Extraction system}

The reference design for the aperture geometry of ELISE is based on the SINGAP design for extraction and pre-acceleration [10], using ø $14 \mathrm{~mm}$ apertures arranged in the same pattern ( 4 groups with $5 \times 16$ apertures) per segment. The aperture spacing is $20 \mathrm{~mm} \times 20 \mathrm{~mm}$. Due to the good results with chamfered apertures on BATMAN [2] the aperture shape for the plasma grid of ELISE will be modified with a $80^{\circ}$ chamfer 
on the plasma side. An overview of the aperture geometry of all grids is presented in figure 6 .

The position of the plasma grid apertures is machined with a pre-offset based on the following considerations: The extraction grid and the grounded grid will be operated at $55^{\circ} \mathrm{C}$ (ITER reference value), while the plasma grid will be operated at $(150 \pm 50){ }^{\circ} \mathrm{C}$ to optimize the $\mathrm{H}^{-}$production rate. The machining will therefore be done with a pre-offset for the plasma grid for $\Delta \mathrm{T}=95^{\circ}$. For standard operation all apertures will then be in line, steering by aperture offset is not planned on ELISE. The remaining expansion for the operating range of $+/-50^{\circ} \mathrm{C}$ causes a maximum aperture offset for the outermost aperture of $0.17 \mathrm{~mm}$ in vertical direction and $0.56 \mathrm{~mm}$ in horizontal direction. The effect on beamlet deflection has been calculated by KOBRA-3D and was found to be just acceptable [11].

All grids will be manufactured by electro deposition of $\mathrm{Cu}$ onto a $\mathrm{Cu}$ base plate with pre-machined cooling channels. This process has been developed and extensively used for positive ion systems for many years.

The grids are mounted electrically isolated onto their grid holder box by using ceramic washers and ceramic sleeves at the fixation points. To allow thermal expansion the grids are clamped down after alignment at one position (close to the cold water inlet), a second position at the outlet side defines the expansion direction by a slot in the grid and the other two positions allow free expansion in all directions.

The magnetic filter field in front of the plasma grid will be produced by a combination of permanent magnets (along the side walls of the source vessel and/or rods between the beamlet groups) and by a current of up to $8 \mathrm{kA}$ driven vertically through the plasma grid (PG current). For this PG current flexible connectors have been designed which feed the current over the whole width to the grid and between the grid segments. The design of the plasma grid was optimized with respect to a homogeneous current density distribution yielding a homogeneous magnetic field across the source width; details are presented in [12].

The power loads onto the grids are summarized in table 2 and have been used for the design of the cooling circuits. 


\subsection{Plasma Grid}

The power load on the plasma grid is significantly lower for $\mathrm{rf}$ sources than for arc sources and has been estimated from BATMAN experiments to be $20 \mathrm{~kW} / \mathrm{m}^{2}$. In addition the ohmic heating from the PG current has to be considered with $2 \mathrm{~kW}$ per segment.

The plasma grid will be operated at temperatures up to $200^{\circ} \mathrm{C}$, therefore its temperature will be actively controlled by a separate cooling system with pressurized water at 20 bar (outlet counter pressure).

To reduce the temperature gradient within the grid and thereby minimizing the distortion of the grid a cooling scheme has been developed as shown in figure 7. Two comb like manifolds, one each for inlet and outlet, are placed between the beamlet groups. Small channels between each aperture row connect these inlet and outlet submanifolds and heat the water only in that small area of 5 apertures. The out of plane deformation could be reduced to $0.14 \mathrm{~mm}$

The plasma grid will be PVD coated with $\mathrm{a} \sim 3 \mu \mathrm{m}$ thick Mo layer on the plasma side.

\subsection{Extraction Grid}

The power load on the extraction grid is the most critical one as the co-extracted electrons are deflected onto it. In order to have some safety margin during the conditioning phase ( in $\mathrm{D}^{-}$) the maximum power load of the co-extracted electrons onto the extraction grid was assumed to be twice the ion current density times the extraction voltage of $10 \mathrm{kV}$ resulting in $400 \mathrm{~W} / \mathrm{cm}^{2}$ (power density per aperture area). That value is frequently reached at BATMAN and therefore taken as design value [4]. The power load distribution on the grid surface is strongly inhomogeneous according to the electron trajectories and was calculated for SINGAP with a maximum of 16 $\mathrm{MW} / \mathrm{m}^{2}$ [13]. For the ELISE design also this power load distribution was doubled to $32 \mathrm{MW} / \mathrm{m}^{2}$.

The aim of the design (figure 8) was to tolerate the above heat loads and to reduce the out of plane deformation to a minimum. Therefore the cooling of one grid segment is split into two circuits, each one supplying only one half of the segment. Between each row of apertures three channels are placed, two curved and one straight to cover most of the grid surface between the apertures. The cooling channels are 1 
$\mathrm{mm}$ wide and $2 \mathrm{~mm}$ deep, minimum wall thickness is $1 \mathrm{~mm}$. The curved cooling channels are enlarged between the beamlet groups in order to keep the pressure loss similar to that of the straight channels. This design increases the heat exchange surface and reduces the grid temperature by $22 \%$ and the out of plane bending by $30 \%$ compared to the ITER reference design with one straight channel $(5 \mathrm{~mm}$ wide and 2 mm deep).

Calculations with CFD (Computational Fluid Dynamics) show that the water velocity in the cooling channel is $12 \mathrm{~m} / \mathrm{s}$, in the manifolds between 5 and $7 \mathrm{~m} / \mathrm{s}$, respectively. The pressure drop for one circuit is 7.6 bar.

Grooves for electron deflection magnets are embedded between each row and column of apertures in vertical as well as in horizontal direction thus allowing a flexible magnet configuration from parallel to orthogonal w.r.t. the filter field (figure 8). The magnets can be inserted through window openings on the back side which will be closed by screwed on cover plates.

\subsection{Grounded Grid}

The power load on the ELISE grounded grid - corresponding to the preacceleration grid at SINGAP — has been estimated from the BATMAN and MANITU experience to be $10 \%$ of the total power, for ELISE that is $60 \mathrm{~kW}$ per grid segment. The cooling scheme is similar to the plasma grid scheme to maintain the same advantages of low pressure drop and temperature uniformity.

\subsection{Bias Plate}

The installation of a bias plate enhanced the extracted negative ion current significantly on the test facility BATMAN $[3,5]$ and was essential for deuterium experiments. For ELISE a cooled bias plate is foreseen as an option with no individual apertures but "window frame" like openings around the beamlet groups (figure 9). The windows are $12.5 \mathrm{~mm}$ larger than the outer edge of the apertures in all directions. The bias plate is mounted $7 \mathrm{~mm}$ above the plasma grid and electrically insulated against the source body and the plasma grid so that the potential of the plate can be controlled separately. The plasma side will be coated with molybdenum. 


\section{Main Insulator}

The ELISE source is at $60 \mathrm{kV}$ and has to be supported and electrically insulated from ground potential. This has to be done by a main insulator of an inner diameter of $1.3 \mathrm{~m}$. As a ceramic cylinder of that size was not available in industry, an alternative solution is foreseen as shown in figure 10. A circular glass plate, $(15 \mathrm{~mm}$ thick, ID $1300 \mathrm{~mm}$, OD $1700 \mathrm{~mm}$ ) will act as vacuum boundary and high voltage insulation providing clean vacuum condition, while on the outside all mechanical forces will be taken from large epoxy supports which are in air. Those epoxy supports have to be machined precisely during manufacturing to position the outer and the inner support ring of the glass plate within a planarity tolerance of $0.3 \mathrm{~mm}$ not to induce unallowable stresses into the glass plate.

The glass itself is floating on O-rings between the steel flanges, not touching the steel rings. Even under vacuum the remaining gap between glass and steel is $\sim 1.6$ $\mathrm{mm}$. These values have been evaluated with compression tests of the O-ring in a small mockup.

Calculations of the electric fields have been carried out to optimize the geometry and to keep the field strength below the critical values of $1 \mathrm{kV} / \mathrm{cm}$ at the triple point and $10 \mathrm{kV} / \mathrm{cm}$ on the insulator surface.

To test this main insulator design and the high voltage holding capability (even with parallel magnet fields), a mockup has been built with a glass plate of OD 500 $\mathrm{mm}$ and ID $100 \mathrm{~mm}$. The radial width of the glass plate as well as the shape of electrodes and the length of the epoxy supports is identical to the ELISE size. The tests have been performed successfully, breakdown occurred at $90 \mathrm{kV}$ between the flanges of the glass plate on the air side.

\section{Summary}

The test facility ELISE with beam extraction from a half-size ITER source is a very important intermediate step between the existing small $\mathrm{rf}$ sources and the full size ITER source. It will support the design of the ITER NBI and test facilities and will help to gain early experience with beam extraction from large rf sources.

The design stays as close as possible to the ITER design with some modifications for flexibility and diagnostic access. Therefore the source will be 
operated in air and has to be a vacuum containment; nevertheless the drivers can be operated in vacuum.

The extraction system has been modified according to IPP experience: the plasma grid will have a significantly lower power load and will have $80^{\circ}$ chamfers on the plasma side. For the extraction grid the cooling channels have been upgraded in order to cope with twice the nominal power and to reduce the out of plane bending of the grid. An additional bias plate has been installed as this was very beneficial in deuterium operation at BATMAN to reduce the filter field strength. All inner surfaces of the source are PVD coated with $3 \mu \mathrm{m}$ molybdenum.

The main insulator with an inner diameter of $1.3 \mathrm{~m}$ was realized by separating its function: a planar glass ring floating between O-rings forms a clean vacuum containment while the mechanical forces are taken by massive epoxy blocks on air. It is planned to manufacture and assemble the test facility within two years from the start of the project.

\section{Acknowledgements:}

This work was supported by a grant (03FUS0002) from the German Bundesministerium fuer Bildung und Forschung as well as by a grant (TW6-THHNRSFD4) from the European Union within a framework of EFDA (Europian Fusion Development Agreement). This support is gratefully acknowledged. The authors are solely responsible for the content. 


\section{References:}

[1] Stäbler, A. et al, Development of a RF-driven ion source for the ITER NBI system, SOFT conference 2008, to be published in Fusion Eng. Des.

[2] Speth E. et al, Overview of the RF source development programme at IPP Garching, Nuclear Fusion 46 (2006), S220

[3] Franzen P. et al, Progress of the development of the negative ion source for the ITER neutral beam system, Nuclear Fusion 47 (2007), S264

[4] Franzen P. et al, Physical and experimental background of the design of the ELISE test facility, Proceedings of the 1st International Conference on Negative Ions, Beams and Sources (NIBS), Sept. 2008

[5] Kraus W. et al, Long pulse large area beam extraction with an $\mathrm{RF}$ driven $\mathrm{H}^{-} / \mathrm{D}^{-}$ source, Review of Scientific Instruments 79(2): C2108, 2008

[6] Duesing G. et al, Neutral Beam Injection System, Fusion Technology volume 11, p 163 (1987)

[7] Fubiani G. et al, Modelling of secondary emission processes in the negative ion based electrostatic accelerator of the International Thermonuclear Experimental Reactor, Physical Review Special Topics - Accelerators and Beams 11, 014202, 2008

[8] Kraus W. et al, Development of RF driven $\mathrm{H}^{-} / \mathrm{D}^{-}$sources for ITER, Proceedings of the 35th EPS Conference, June 2008

[9] Riedl R. et al, Design and Manufacturing of a CW Faraday Shield for the RF Negative Ion Source, SOFT conference 2008, to be published in Fusion Eng. Des.

[10] De Esch, H.P.L.. et al, Updated physics design ITER-SINGAP accelerator, Fusion Engineering and Design 73 (2005) 329-341

[11] Gutser R. et al, Simulations for the generation and extraction of negative hydrogen ions in RF-driven ion sources, Proceedings of the 1st International Conference on Negative Ions, Beams and Sources (NIBS), Sept. 2008

[12] Nocentini R. et al, Plasma grid design for optimized filter field configuration for the NBI test facility ELISE, SOFT conference 2008, to be published in Fusion Eng. Des.

[13] De Esch, H.P.L., private communication 
Table 1: Parameters of ELISE.

\begin{tabular}{l|l} 
Isotope & $\mathrm{H}, \mathrm{D}$ (limited) \\
\hline Extraction Area & $1000 \mathrm{~cm}^{2}$ \\
\hline Apertures & $\begin{array}{l}640,2 \times 4 \text { groups, } \varnothing 14 \mathrm{~mm}, \\
\text { spacing } 20 \mathrm{~mm}^{2} 20 \mathrm{~mm}\end{array}$ \\
\hline Source Size & $1.0 \times 0.86 \mathrm{~m}^{2}$ \\
\hline $\mathrm{U}_{\mathrm{HV}}$ & $60 \mathrm{kV}$ \\
\hline $\mathrm{U}_{\mathrm{ex}}$ & $<12 \mathrm{kV}$ \\
\hline $\mathrm{P}_{\mathrm{RF}}$ & $360 \mathrm{~kW}$ \\
\hline $\begin{array}{l}\text { Pulse Length: } \\
\text { Plasma }\end{array}$ & $\begin{array}{c}3600 \mathrm{~s} \\
\text { Extraction }\end{array}$ \\
\hline
\end{tabular}

Table 2: Design values of power loads per grid segment

\begin{tabular}{|l|c|}
\hline & Heat Load per grid segment \\
\hline Grid & ELISE \\
\hline Plasma grid & $7.5 \mathrm{~kW}^{(1)}+2 \mathrm{~kW}^{(2)}=9.5 \mathrm{~kW}$ \\
\hline Extraction grid & $200 \mathrm{~kW}^{(3)}$ \\
\hline Grounded grid & $60 \mathrm{~kW}^{(4)}$ \\
\hline
\end{tabular}

(1) Power density on PG: $20 \mathrm{~kW} / \mathrm{m}^{2} \times$ grid surface (1 segment) $\approx 0,38 \mathrm{~m}^{2}$

(2) PG Filter ohmic heating ( $8 \mathrm{kA} \times 0.2 \mathrm{~V}$ for $\mathrm{Cu}$ grid)

(3) Electron current $=400 \mathrm{~A} / \mathrm{m}^{2}$ (safety factor: 2$) \times$ Voltage $=$ $10 \mathrm{kV} x$ extraction surface (1 segment) $\approx 0,05 \mathrm{~m}^{2}$

(4) $10 \%$ of total Power $(1 \mathrm{~A} \times 60 \mathrm{kV}) \Leftarrow \mathrm{IPP}$ experience 
Figure captions

Fig. 1: Overview of ELISE test facility.

Fig. 2: ELISE source with the extraction system and the HV insulation

Fig. 3: Source vessel showing deep drilled cooling channels and manifolds

Fig. 4: Design of cooling loops of the driver plate

Fig. 5: Design of the ELISE driver, right side complete assembly, left side exploded view from inside

Fig. 6: Aperture geometry of ELISE

Fig. 7: Plasma grid cooling scheme. The green arrows indicate the expansion directions

Fig. 8: Extraction grid of ELISE. Top: Segment front side with cooling circuits. Bottom: back side with magnet grooves for horizontal and vertical orientation

Fig. 9: Bias plate segment with window frame like openings and embedded cooling channels. It is screwed electrically insulated onto the PG

Fig. 10: Main insulator, force flow through epoxy blocks, vacuum boundary along glass plate 


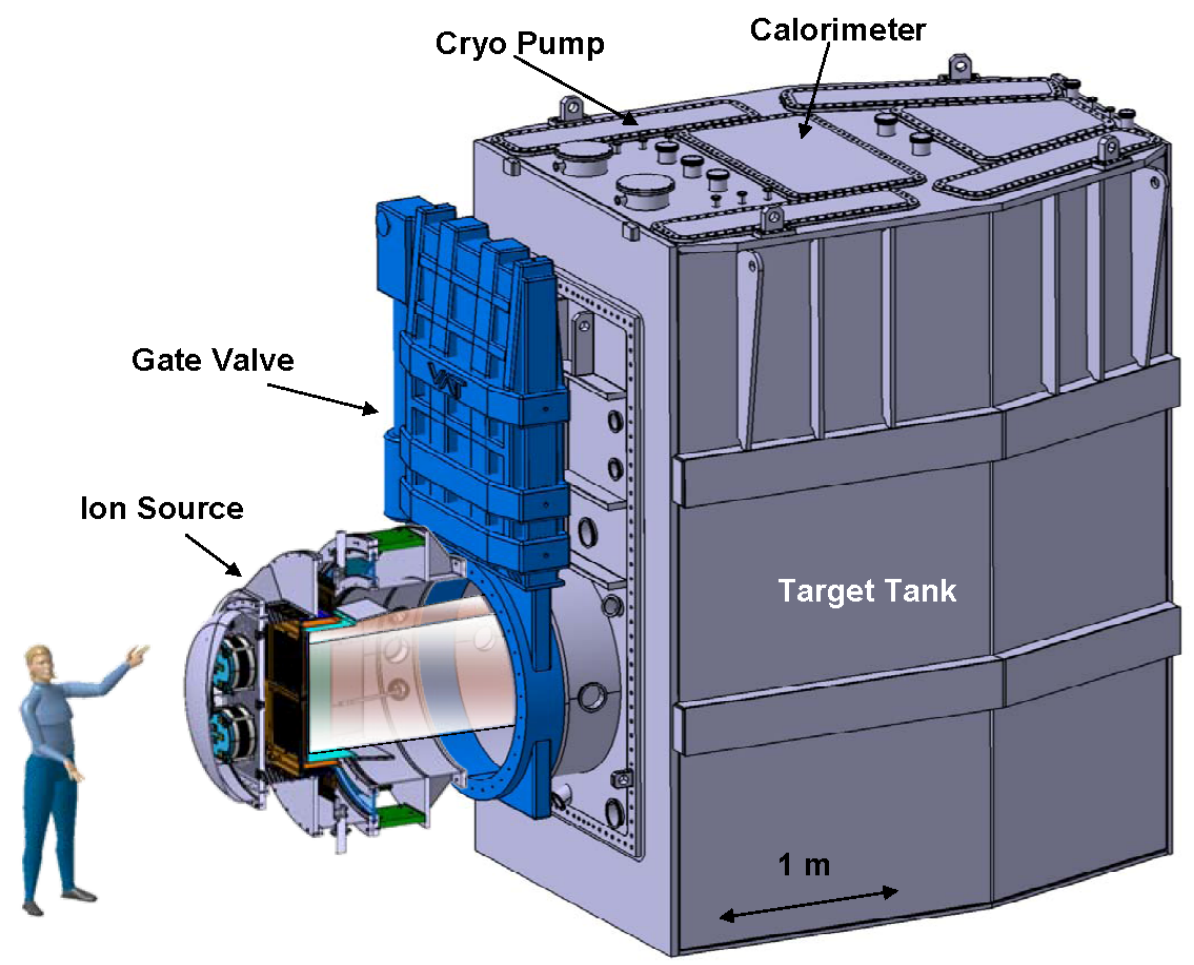

Fig. 1: Overview of ELISE test facility 


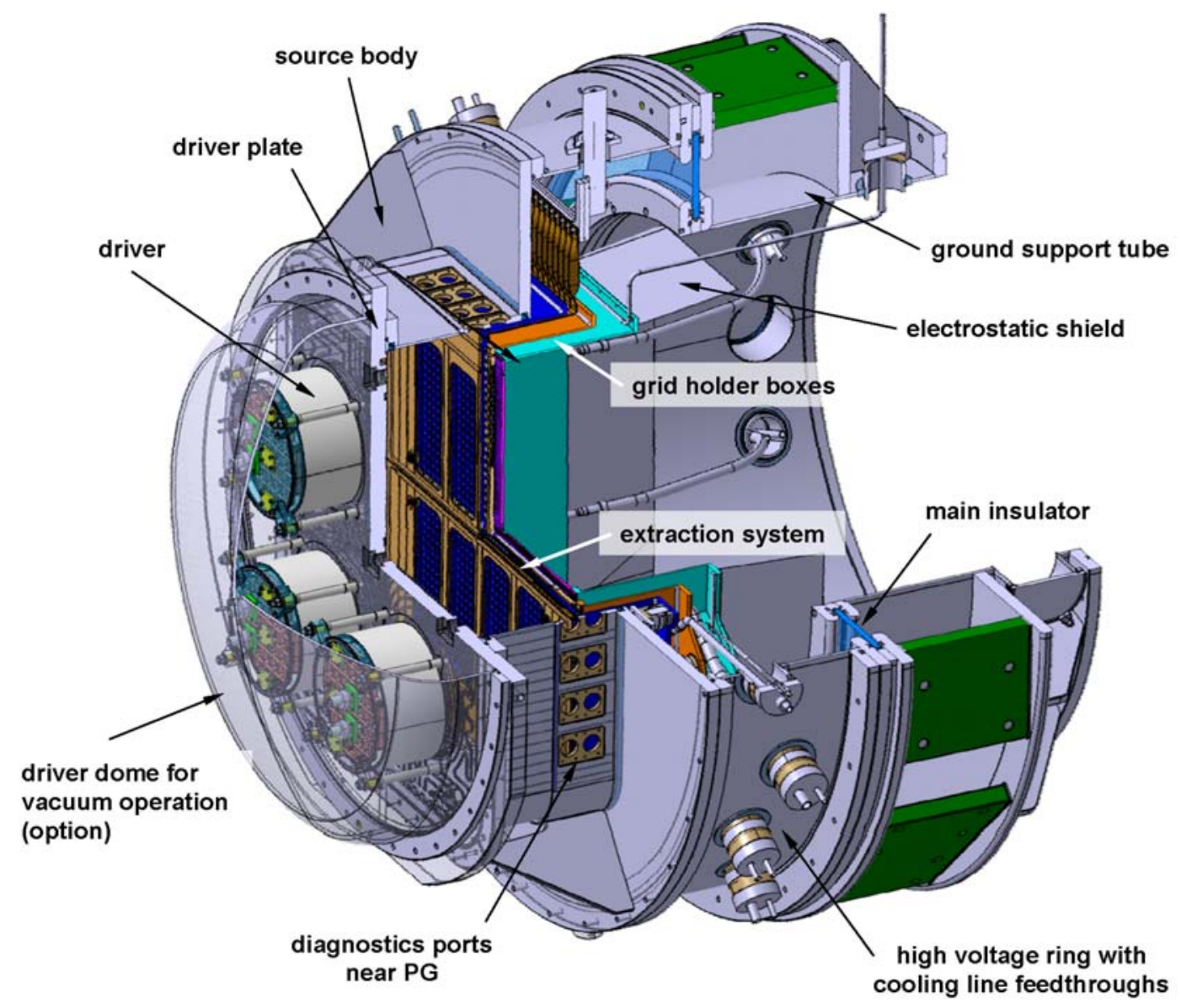

Figure 2: ELISE source with the extraction system and the HV insulation. 


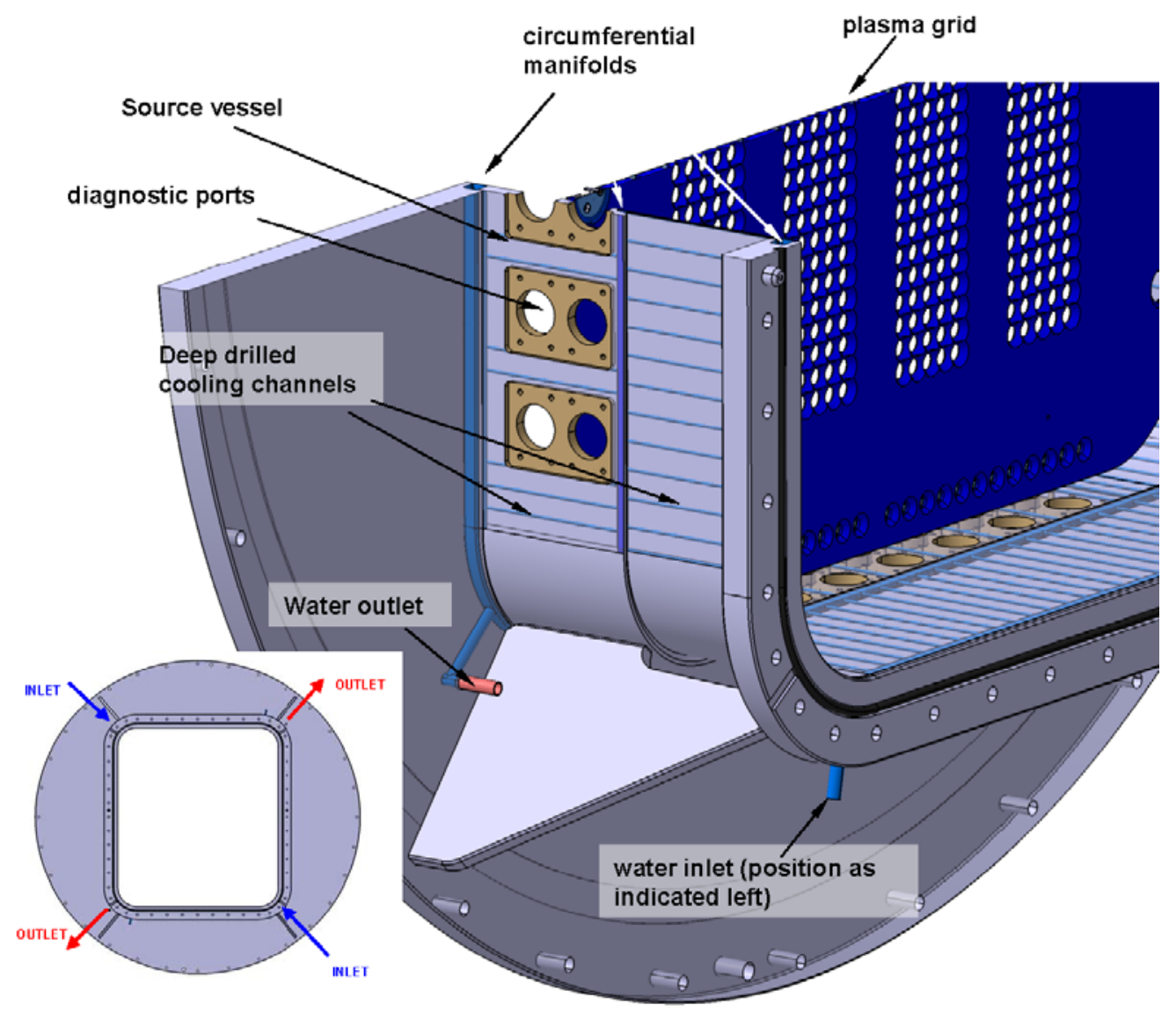

Figure 3: Source vessel showing deep drilled cooling channels and manifolds. 


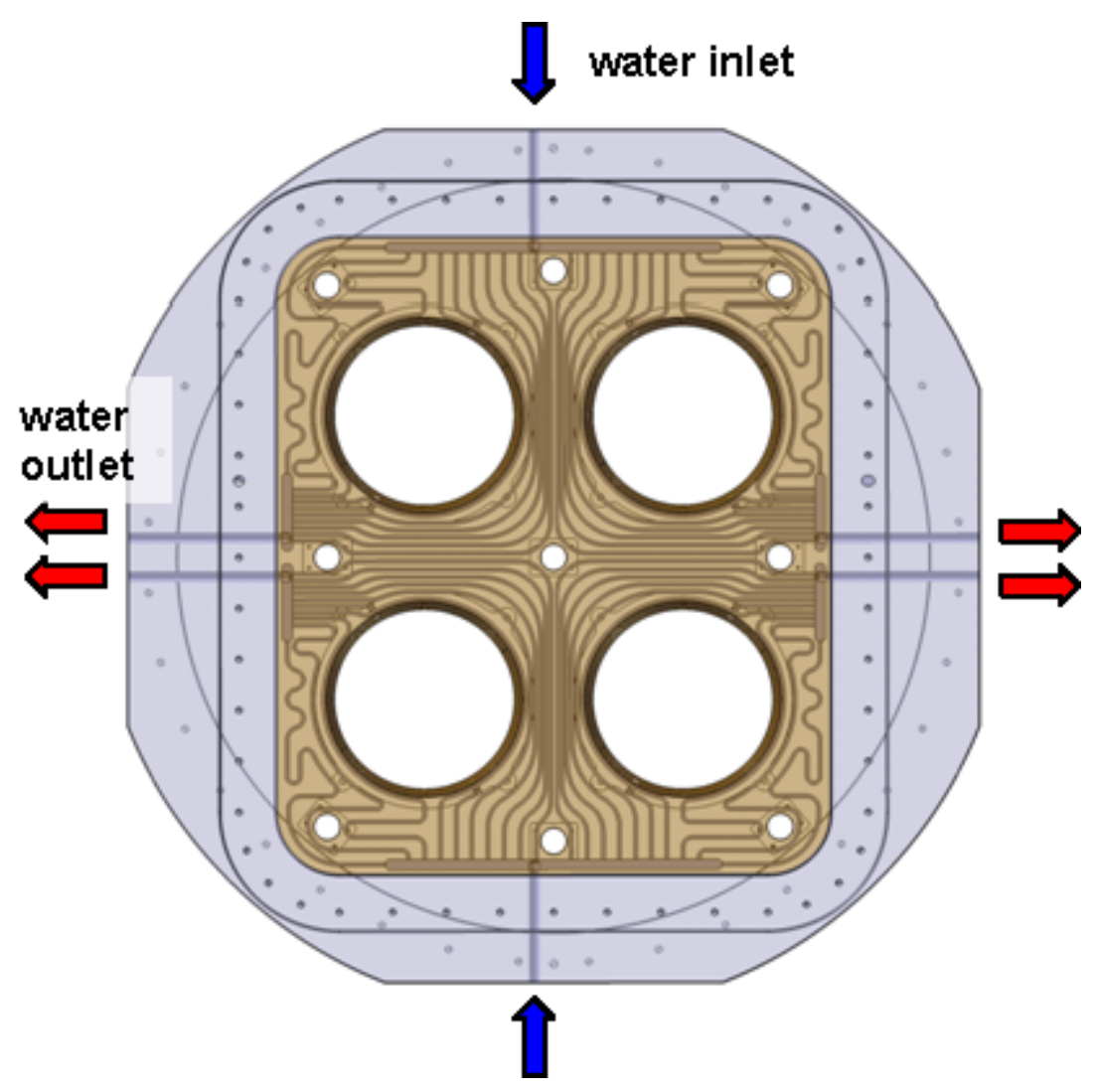

Figure 4: Design of cooling loops of the driver plate 


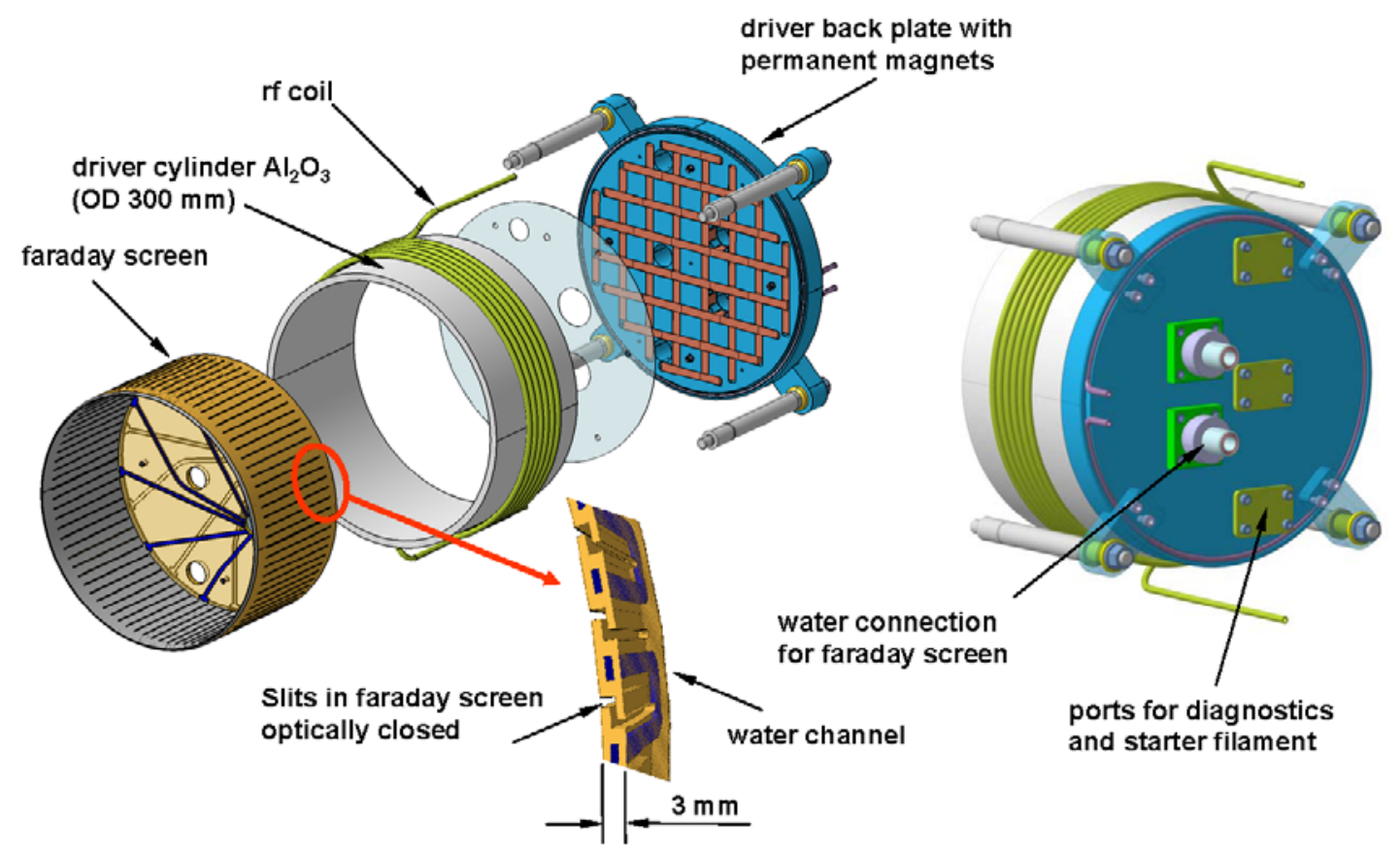

Figure5: Design of the ELISE driver, right side complete assembly, left side exploded view from inside 


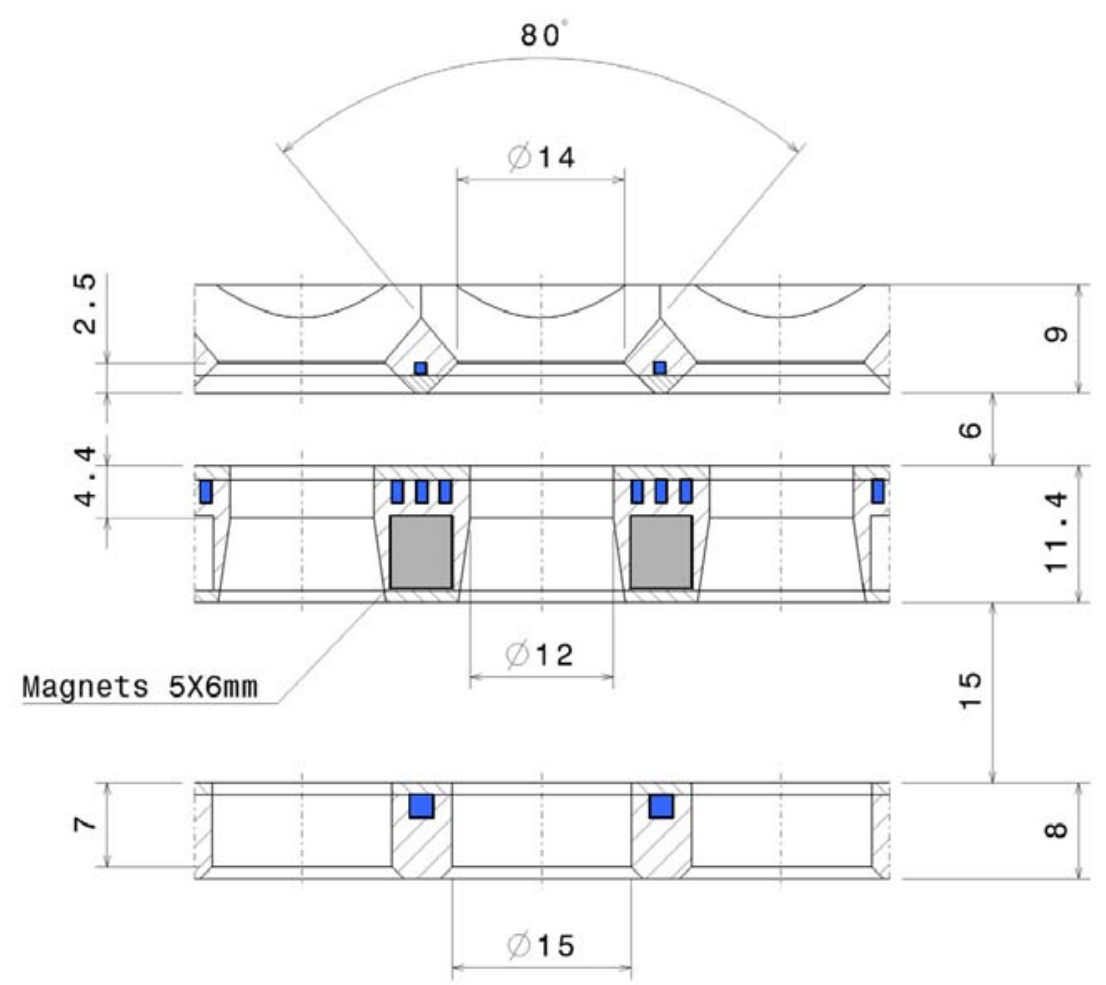

Figure 6: Aperture geometry of ELISE 


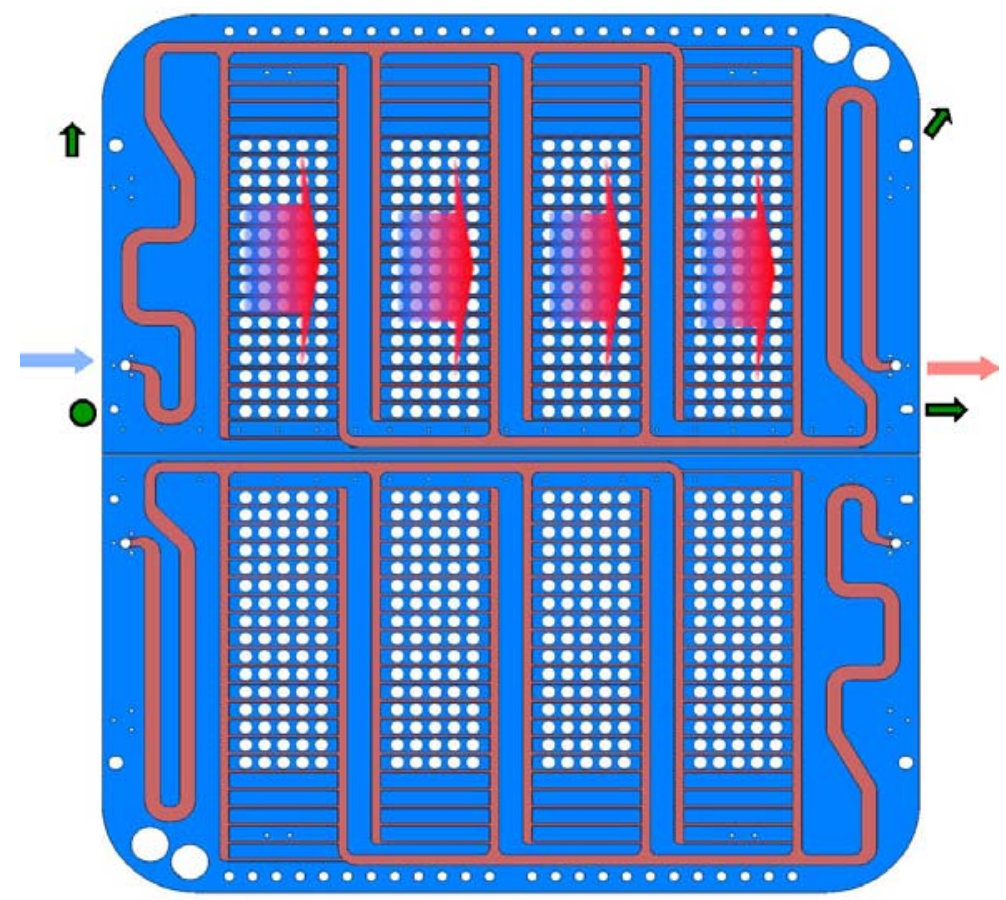

Figure 7: Plasma grid cooling scheme. The green arrows indicate the expansion directions. 


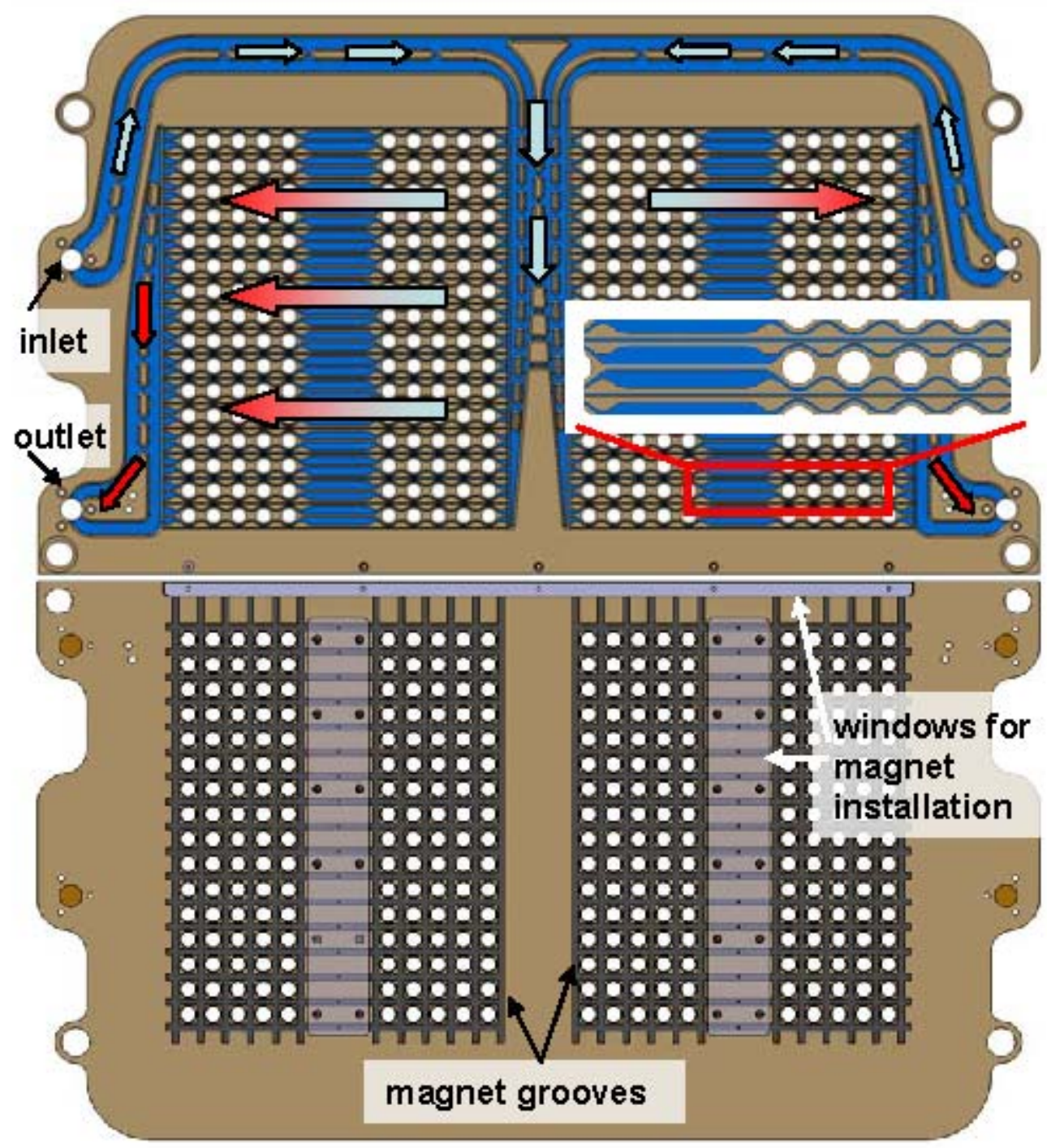

Figure 8: Extraction grid of ELISE. Top: Segment front side with cooling circuit. Bottom: back side with magnet grooves for horizontal and vertical orientation. 


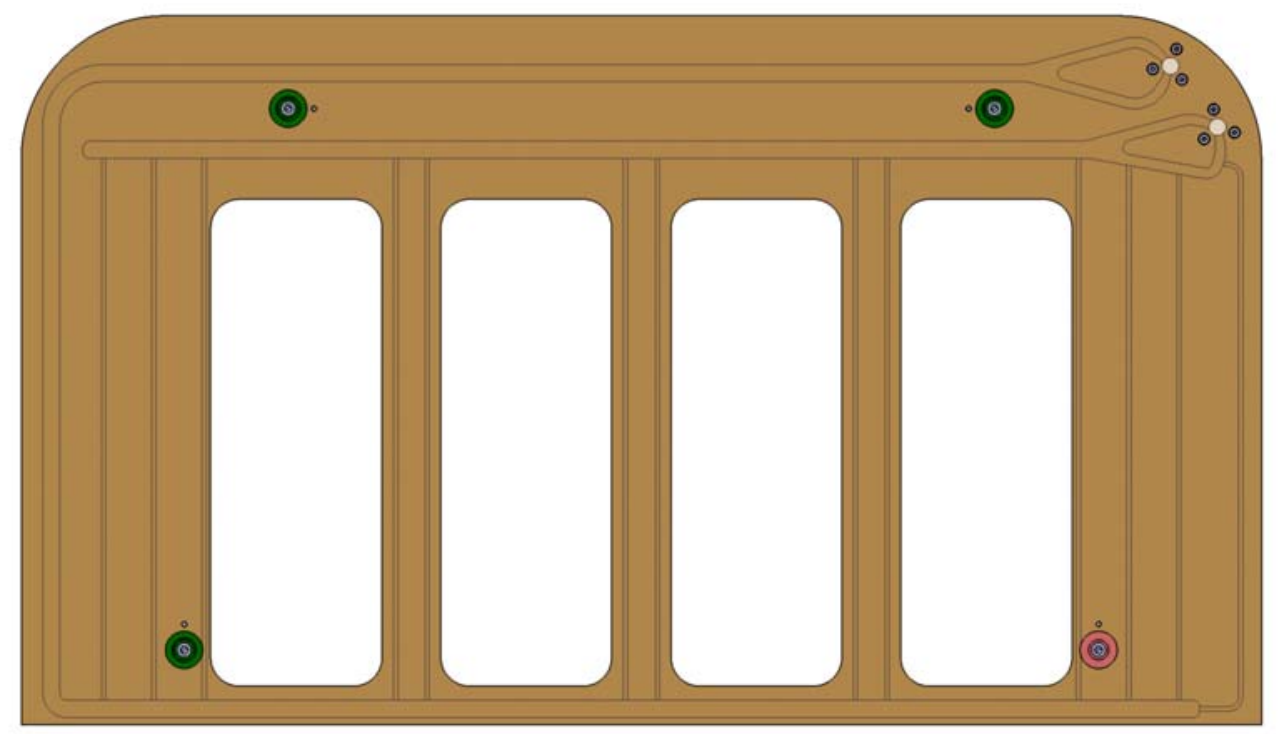

Fig 9: Bias plate segment with window frame like openings and embedded cooling channels. It is screwed electrically insulated onto the PG 


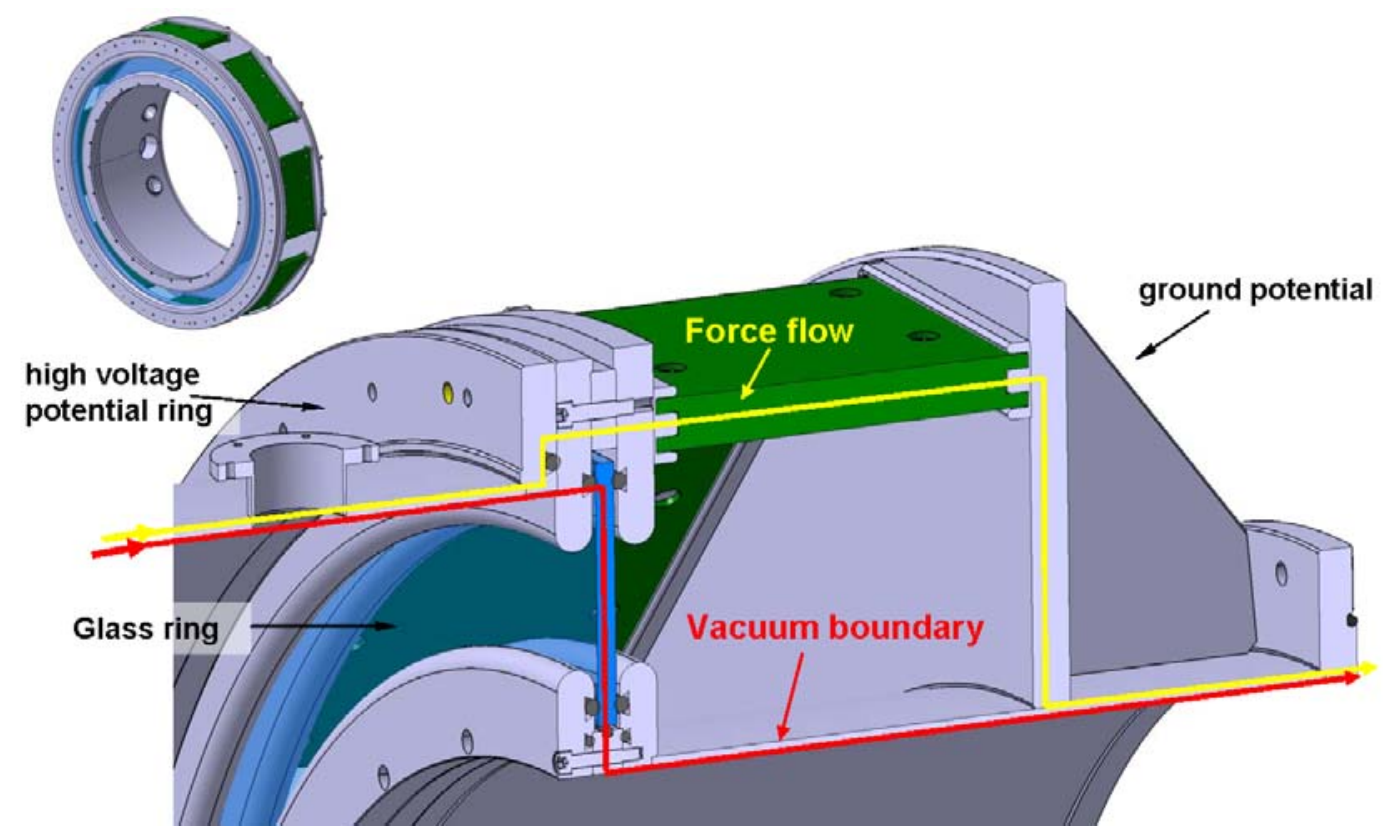

Figure10: Main insulator, force flow through epoxy blocks, vacuum boundary along glass plate 